Proceedings

\title{
Role of Pollution Prevention Activities to Improve Public Health and Well Being
}

\author{
Saisantosh Vamshi Harsha Madirajuํㅜ and Ashok Kumar 1,* \\ 1 Department of Civil and Environmental Engineering, College of Engineering, The University of Toledo, \\ Toledo, OH, USA 43606 \\ * Correspondence: Ashok.Kumar@utoledo.edu
}

Publisher's Note: MDPI stays neutral with regard to jurisdictional claims in published maps and institutional affiliations.

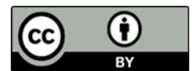

Copyright: (c) 2020 by the authors. Submitted for possible open access publication under the terms and conditions of the Creative Commons Attribution (CC BY) license (http://creativecommons.org/licenses/by/4.0/).

\begin{abstract}
Breathing is as spontaneous as your heartbeat, but if you live in a polluted environment, every breath could be harmful to your health. Pollution in any form or from any source may cause a significant risk to human life. Environmental laws related to air, land, and water are used to regulate the release of hazardous and toxic chemicals throughout the globe. The US Environmental Protection Agency started developing the toxic release inventory (TRI) after the Bhopal accident at the Union Carbide plant in India. This study examines the reduction in emission levels and associated health risks due to the release of contaminants in the US using TRI data. The health risk is calculated using the Risk- Screening Environmental Indicator (RSEI) introduced by USEPA. The RSEI score value determines the dose of exposure of toxic chemicals to the human population. The risk values are presented for cancer as well as for non-cancer health effects. The trend in risk over time is compared qualitatively to the deaths and death rates due to air pollution. This study shows that the health risk associated with industrial pollution is constantly declining over time in the US. One of the reasons for the reduction of the pollutant levels and associated risk is the introduction of Pollution Prevention (P2) programs by the USEPA involving source reduction, energy recovery, and waste reduction. The P2 activities undertaken by the USEPA to minimize the risk are mentioned in this study. The significant relationship between the different types of RSEI scores and deaths from ambient air pollution due to particulate matter is analyzed using correlation analysis. The results indicate that deaths from outdoor particulate matter pollution are significantly correlated with RSEI scores associated with modeled media than the total RSEI scores. The implementation of P2 activities can be one of the most possible reasons. Thus, it can be said that the health and well-being of the entire US population have benefitted from the reduction of industrial pollutant levels as evidenced by environmental risk and death rates.
\end{abstract}

Keywords: Pollution Prevention; Air Pollution; Public Health; RSEI

\section{Introduction}

Breathing dirty air is bad for human health and negatively affecting the heart, lungs, and brain. Recognition of this fact has caused many nations to take legislative action and adopt policies to clean up the air. Many developing countries along with the developed countries face high levels of air pollution from a combination of man-made and natural sources. The awareness of the health effects due to high exposure levels of pollutants is increasing all around the world [1]. Air quality monitoring activities have increased to quantify pollutant levels [2].

Toxic chemicals are released daily into the environment from different sources throughout the earth. The major sources of pollution in the US are (i) natural sources (includes lightning, volcanos, wildfires, and forests), (ii) area sources (includes agriculture, livestock, and cities), (iii) stationary sources (includes industry, power plants, and sewage 
treatment plants), and (iv) mobile sources (includes automobiles and airplanes). Industries are major contributors to the stationary point source category [3].

Major industrial accidents and incidents encountered in the past created the need to protect the environment. Examples of these include: (i) an automobile company dumped more than 35,000 tons of toxic paint sludge onto lands, 43 years ago in Ringwood, New Jersey poisoning groundwater with arsenic and lead, (ii) an aquifer along with the surface water is contaminated with heavy metals due to lead and zinc mining, (iii) 60 years ago at Picher, Oklahoma polluting the surface water and groundwater, and (iv) toxic waste bubbled up into a residential area in "Love Canal Incident" at New York State (1978) [4].

USEPA started the development of a toxic release inventory (TRI) after the Bhopal accident in India in 1984. The purpose of TRI is to encourage P2 activities and to reduce exposure to chemicals. TRI covers eight major industrial sectors that include chemicals, primary metals, electric utilities, food, paper, metal mining, petroleum, hazardous waste, and all other sectors of concern to data users [5]. Data are credible with quality suitable for TRI data users. The information provided in TRI is accessible, understandable, and is used to promote environmentally beneficial dialogue and decision-making. TRI overlaps with the programs related to air, water, and waste at USEPA. It overlaps with the reporting requirements of the Resource Conservation and Recovery Act, National Emissions Inventory, Risk management plan, Greenhouse gas reporting program, Permit Compliance System, and ICIS - NPDES - CWA. TRI data program tracks the management of toxic chemicals that may pose a threat to human health and the environment [6]. It is important to keep in mind that while TRI includes information on a large portion of the chemicals used by industry, it does not cover all facilities, all toxic chemicals (for example, chemicals in consumer products, exhaust from cars and trucks, chemical residues in food and water). The emissions into the air, water discharges, land disposal, transferred off-site disposal or release comes under the "release of a chemical".

The chemicals released affect the environment and public health in one or another way. The chance of adverse effects resulting from exposure to an environmental pollutant to human health and ecological systems is called risk. The USEPA has introduced the Risk Screening Environmental Indicators (RSEI) score to get an idea of risk due to toxic chemical releases from industrial facilities. The size of the chemical release, chemical relative toxicity, chemical transport and consequences, exposed population characteristics, and ground-level concentrations are considered in the calculation of RSEI scores [7].

Around 650 chemicals are covered in the TRI program [7]. In general, the chemicals reported to TRI have acute/chronic human health effects and significant adverse environmental effects, which may also include cancer that ultimately affects morbidity and mortality. According to National Cancer Institute (NCI), morbidity refers to having a disease or a symptom of a disease or to the amount of disease within a population and mortality refers to the state of being mortal or the number of deaths in a certain group of people in a certain period [8]. It is important to have data available to the public to compare death rates between different population groups and geographic locations within the country [9].

Mortality data collected by the government at various geographic locations across the country and characterized occurrence deaths or resident deaths [10]. Occurrence deaths are the deaths that occurred in the country regardless of the country of residence. Data are available from the National Center for Health Statistics (NCHS) categorizing based on public, researchers, survey participants, media, students, and librarians. NCHS develops data collection, processing specifications, and analysis methods [11].

The report on the environment by USEPA presents risk factors of the nine health outcomes indicators due to environmental exposures and for which nationally representative data available [12]: Asthma, Birth Defects, Cancer, Cardiovascular Disease, Childhood Cancer, Chronic Obstructive Pulmonary Disease, Infectious Diseases, Low Birthweight, and Preterm Delivery. All indicators are based on vital statistics and surveillance 
data from the National Cancer Institute and the Centers for Disease Control and Prevention. All the human diseases and its condition indicators are divided into five categories in the health outcomes covered by the report on the environment: They are:
a) Cancer
b) Cardiovascular Disease
c) Respiratory Disease
d) Infectious Disease
e) Birth Outcome

This paper focuses on the identification of the impact of P2 activities on human health. The reduction of health risk to the public is computed by comparing the cancer risk calculated using TRI emission data, deaths due to air pollution from the web site "Our World in Data" (a project of the Global Change Data Lab, a registered charity in England and Wales with a Charity Number 1186433) and data on carcinogens from the National Cancer Institute (US Department of Health and Human Services) over time.

\section{Carcinogenic pollutants}

The result in changes to the RNA that alter the cell's function is Cancer. It may occur naturally during the cell division process [13]. But other DNA damages are the result of some environmental exposures [14]. These exposures may include chemicals in tobacco smoke, ultraviolet radiation from the sun, traffic pollution, industrial pollution, etc. Tobacco smoke and the sun's rays can be avoided by the people, but they can't avoid some cancer-causing exposures, but if they are in the air, water and food we consume or the materials at our jobs are harder to avoid [15]. Researchers are examining which exposures may lead to cancer development or harmful, to help people by eliminating them [16]. The substances which are among the most likely carcinogens to affect human health listed below, according to the National Toxicology Program's 14th Report on Carcinogens [17]. A substance that has been designated as a carcinogen does not mean that the substance will necessarily cause cancer. There are many other factors. which includes the amount and duration of the exposure and the individual's genetic background [18]. The list of some carcinogens mentioned in Table 1.

Table 1. List of carcinogens according to the National Toxicology Program's 14th Report.

\begin{tabular}{lll}
\hline - & Aflatoxins & Aristolochic Acids \\
- Arsenic & Coal Tar and Coal-Tar Pitch \\
- Asbestos & Coke-Oven Emissions \\
- & Benzene & Crystalline Silica (respirable size) \\
- & Benzidine & Hexavalent Chromium Compounds \\
- & Beryllium & Indoor Emissions from the Household Combustion of Coal \\
- & $1,3-B u t a d i e n e$ & Mineral Oils: Untreated and Mildly Treated \\
- & Cadmium & Nickel Compounds \\
- Erionite & Secondhand Tobacco Smoke \\
- & Ethylene Oxide & Environmental Tobacco Smoke \\
- & Formaldehyde & Strong Inorganic Acid Mists Containing Sulfuric Acid \\
- & Radon & Trichloroethylene \\
- & Soot & Vinyl Chloride \\
- & Thorium & Wood Dust \\
\hline
\end{tabular}

As mentioned earlier many factors cause carcinogenic health effects including exposures from automobiles, industries, tobacco smoke, and other air pollution emission sources. This study considered only the emissions from the industrial sources to calculate RSEI scores and correlated with the death rates from outdoor particulate matter air pollution. 


\section{P2 activities undertaken by USEPA to minimize risk}

The amount of waste to be treated, controlled, and disposed-off is less when there is a decrease in the amount of pollution produced. The reduced pollution also implies a low risk on public health as well as the environment, which are covered in P2 activities. All pollution-generating activities can implement these P2 approaches, which include the energy, agriculture, consumer, and industrial sectors [19]. Table 2 represents major P2 activities included in different sectors, according to USEPA's P2 program:

Table 2. The P2 activities in different sectors as per EPA's Pollution Prevention program.

\begin{tabular}{|c|c|}
\hline Sector & Activities \\
\hline Energy sector & $\begin{array}{l}\text { It can reduce environmental damages from extraction, processing, } \\
\text { transport, and combustion of fuels. } \\
\text { Increasing efficiency in energy use. } \\
\text { Use of environmentally benign fuel sources. }\end{array}$ \\
\hline Agricultural sector & $\begin{array}{l}\text { Reducing the use of water and chemical inputs. } \\
\text { Adoption of less environmentally harmful pesticides or cultivation of } \\
\text { crop strains with natural resistance to pests. } \\
\text { Protection of sensitive areas. }\end{array}$ \\
\hline Industrial sector & $\begin{array}{l}\text { Modifying a production process to produce less waste. } \\
\text { Using non-toxic or less toxic chemicals like cleaners, degreasers, and } \\
\text { other maintenance chemicals. }\end{array}$ \\
\hline & $\begin{array}{l}\text { Implementing water and energy conservation practices. } \\
\text { Reusing materials such as drums and pallets rather than disposing of } \\
\text { them as waste. }\end{array}$ \\
\hline Homes and schools & $\begin{array}{l}\text { Using reusable water bottles instead of throw-always. } \\
\text { Automatically turning off lights when not in use. } \\
\text { Repairing leaky faucets and hoses. } \\
\text { Switching to "green" cleaners. }\end{array}$ \\
\hline
\end{tabular}

P2 reduces both financial costs include waste management \& cleanup and environmental costs include health problems \& environmental damage. Conservation of the environment by protecting natural resources is one of the advantages of P2 projects. They also strengthen economic growth by improving ways to efficient production in the industry $[19,20]$. These activities help households, businesses, and communities to handle the waste. Outcomes of P2 activities are knowledge-based, behavioral, health-related, or environmental, which includes decreased exposure to toxins, conservation of natural resources, decreased release of toxins to the environment, and cost savings.

\section{Methodology}

The study uses a two-step procedure:

Step 1: The emission from industrial sources given in TRI (by USEPA) is used to calculate the RSEI scores to get an idea of risk for the period 2007 to 2017 [21]. The equation to calculate the RSEI score by EPA is given as equation (1).

$$
\text { RSEI Score }=\text { Dose } * \text { Toxicity Weight } * \text { Population }
$$

Step 2: The trend in RSEI scores is qualitatively compared with the death rate results throughout the country for the analysis of health effects due to contaminants released. All the surveillance data and indicators are based on statistics from the Our World in Data [22], National Cancer Institute [23], and Centers for Disease Control and Prevention [24 26]. The emission estimation general equation used by industries to report TRI data is given as equation (2).

$$
E=A * E F *\left(\frac{1-E R}{100}\right)
$$


where,
$\mathrm{E}=$ Emissions
$\mathrm{A}=$ Activity rate
$\mathrm{EF}=$ Emission Factor
$\mathrm{ER}=$ Overall emission reduction efficiency, \%

The emission estimation equation is used to calculate the chemical or facility releases by the industries and report to USEPA as TRI data. The potential relative risk scores are produced by EPA using The Risk-Screening Environmental Indicators (RSEI) model [27]. The industries with the highest releases are identified by the summation of total releases of chemicals from the total reported data and the modeled data. The chemicals are separately plotted over time as per RSEI scores. The death rates and total cancer risk are calculated.

$$
\text { Death Rate }=\frac{\text { Number of Deaths } * 100,000}{\text { Population }}
$$

ArcGIS is used to locate the total industrial facilities reported to TRI on a United States map [28]. Major emitted air pollutants by source are identified and compared with the total emissions. A comparative graph including GDP growth and population by year was developed with the available data [29]. Comparative graphs for cancer risk, non-cancer risk, and total risk-based on RSEI scores. Public health effects and death rate due to ambient, outdoor, particulate air pollution are included in the results and discussion $[30,31]$. A correlation analysis is also provided in the results and discussion to identify the significant relationship between the different types of RSEI scores and deaths from ambient air pollution due to particulate matter.

\section{Results and Discussion}

Approximately 20,000 industries reporting emission information to the USEPA (excluding Hawaii and Alaska) for TRI is represented on the GIS map (see Figure 1). It shows that the concentration of industries is high in the east part of the US. The contribution of major common pollutants (carbon monoxide (CO), oxides of nitrogen (NOx), sulfur dioxide $\left(\mathrm{SO}_{2}\right)$, ammonia $\left(\mathrm{NH}_{3}\right)$, direct particulate matter ( $\mathrm{PM}_{2.5}$ and $\left.\mathrm{PM}_{10}\right)$, volatile organic compounds (VOCs) ) from different sources in TRI is given in Figure 2(a) for 2017 (groundlevel ozone is not included in the graph since it is formed during the reaction in the presence of sunlight between in NOx and VOCs) [32]. All the emissions are classified into four different categories. They are (i) stationary fuel combustion (ii) industrial and other processes (iii) highway vehicles (iv) non-road mobile. The percentage contribution of each pollutant from 1990 to 2017 in total emissions in the US is represented in Figure 2(b). This figure also shows that the carbon monoxide contribution is highest when total emissions from all the sources are considered. Total emissions from all the sources are shown in Figure 2(c). All the emissions were measured in million tons.

The facilities considered in this study comes under the categories of stationary fuel combustion, industrial and other processes. In this research, these are the potential sources to be considered under the facilities reporting to TRI data. The combined percentage of pollutants released from facilities under these categories in the total emissions by all the sources are CO-36.57\%, NH $3-97.48 \%$, SO2-98.14\%, $\mathrm{PM}_{2.5}-83.66 \%$, PM10-82.95\%, NOx$41.95 \%$, VOCs- $82.95 \%$. The population of the US is constantly increasing in the considered period (1990-2017). GDP per capita and population by year are given in Figure 2(d). In general, the figure shows that the GDP per capita is increasing with the increase in population. 
TOTAL INDUSTRIAL FACILITIES IN USA REPORTED TO TRI

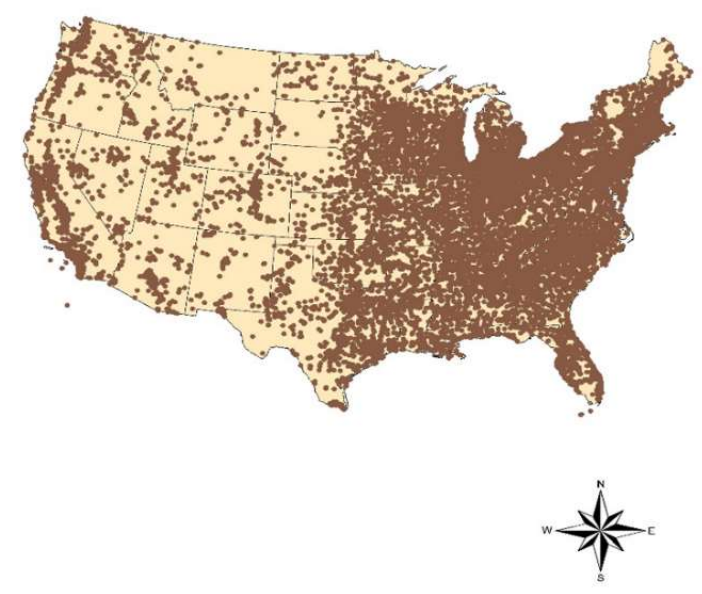

Legend

$\square$ STATES EXCLUDING ALASKA AND HAWAII IN USA.

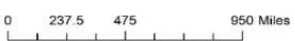

Figure 1. Industrial facilities reported to TRI in the US.

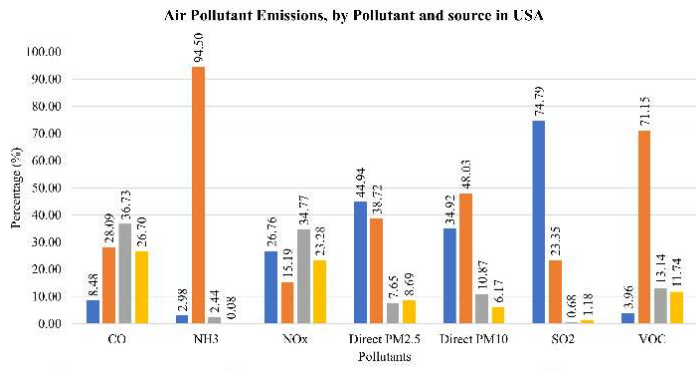

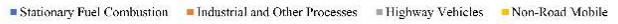

(a)

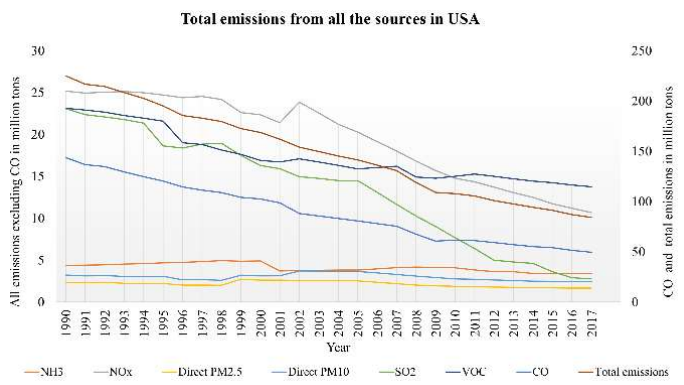

(c)

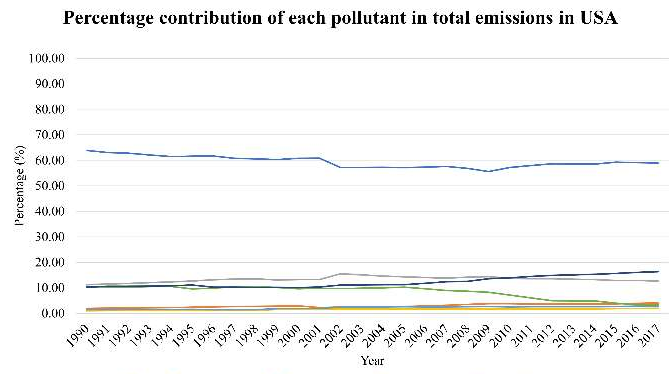

(b)

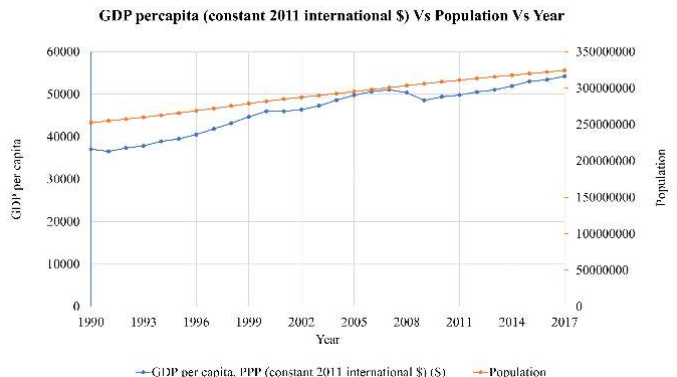

(d)

Figure 2. (a) Air pollutant emissions by source in USA; (b) Percentage contribution of each pollutant. (c) Total emissions from all the sources; (d) Comparison of GDP and Population by year.

RSEI scores are calculated to compare the risk due to each pollutant/chemical. If two chemicals have a difference of 10 times between their RSEI score that means the risk potential is 10 times higher. Similarly, small releases may lead to high RSEI scores in the situation of high toxicity weight or in another case of the greater estimated exposed population. Conversely, high releases may also lead to low RSEI scores in the situation of low toxicity weight or another case small estimated exposed population. The risk in an area may not be particularly due to a high RSEI score chemical or an industrial facility. This 
results in the necessity of detailed investigation in areas with high RSEI scores. At the local level, the change in the RSEI score of a facility reflects the changing population size without changing its releases over time [34]. This indicates that population trends overtime should also be considered in relative risk evaluation when a facility's environmental management practices (or P2 practices) are examined. The risk based RSEI scores are only for the modeled data (facilities reported to TRI releases). However, if unreported releases from facilities are included, there will be a variation in the total risk. The risk for modeled releases and total releases from 2007 to 2017 are represented in Figure 3. Total cancer risk and non-cancer risk has decreased when the statistics from 2007 and 2017 are considered for modeled data. However, a few elevated points in these figures are due to the addition of new chemicals and their compounds in the toxic release inventory. Note that the P2 activities such as reducing pollution at the source by modification of manufacturing processes, switching to eco-friendly maintenance use chemicals, following conservation practices, elimination of single-use plastic, and reusing materials were carried out over the years in industries reporting to TRI [36].

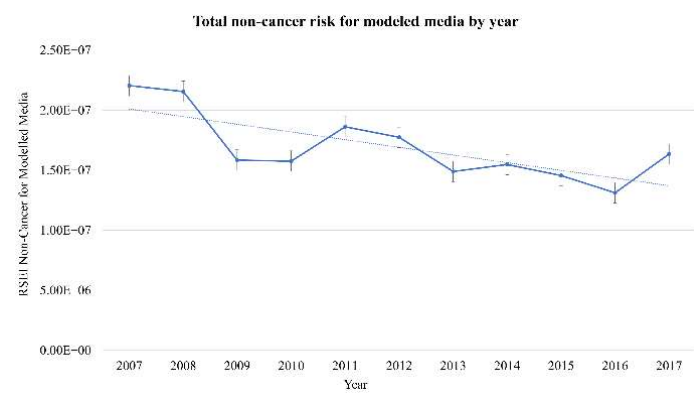

(a)

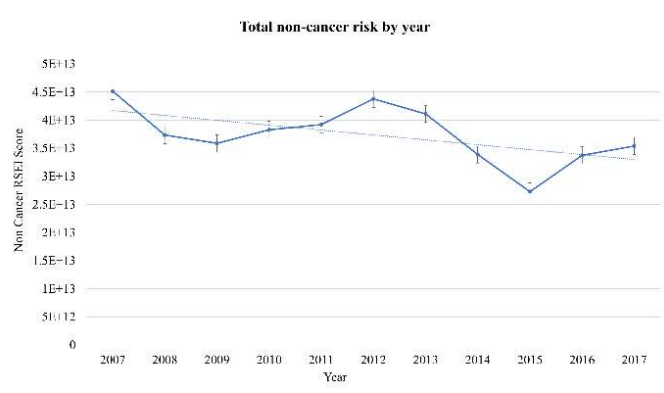

(c)

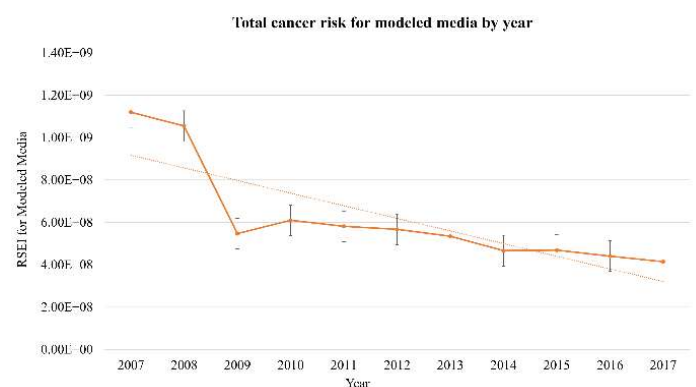

(b)

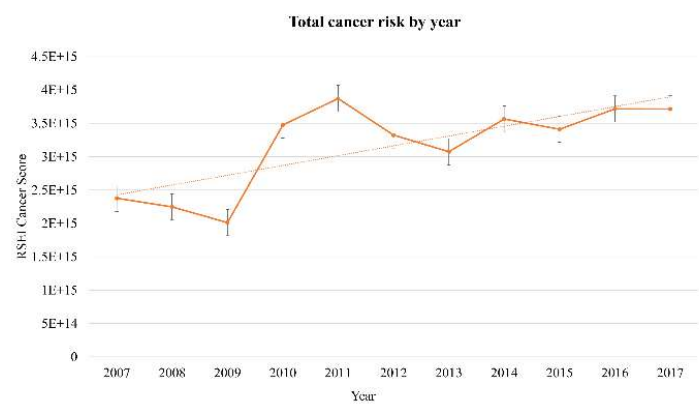

(d)

Figure 3. (a) Non-cancer risk for modeled media; (b) Total cancer risk for modeled media; (c) Non-cancer risk over time for total releases; (d) Total Cancer risk over time for total releases.

The risk trends for total releases from all the industrial facilities reported to TRI data are given in Figures 3(c) and 3(d). The cancer risk trends over time for modeled and total releases shown in Figure 3(b) and Figure 3(d) are different. These graphs show a decreasing trend for modeled releases and while an increased risk for total releases. The decreasing risk trend in modeled releases is attributed to the P2 activities encouraged by USEPA. The increase in total cancer risk in Figure 3(d) is due to the consideration of all the media including modeled media, non-modeled media, and the addition of new chemicals.

Figure 4 represent the total deaths due to air pollution in the US from 1990-2017 based on Our World in Data [37]. The graphs indicate that the air pollution levels and death rate due to air pollution for a given air pollutant are decreasing by the year. Note that the GDP growth and the population are increasing simultaneously during this period as shown in Figure 2(d). 


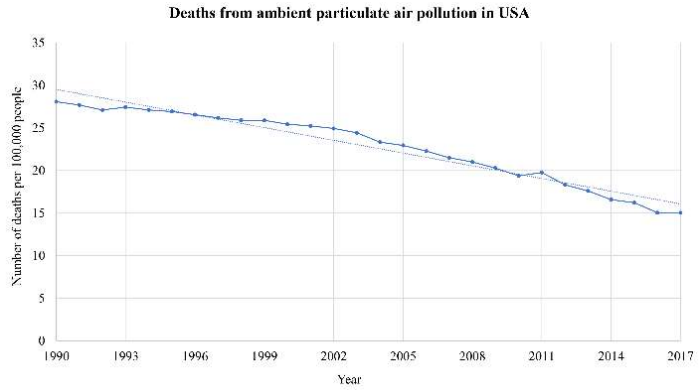

(a)

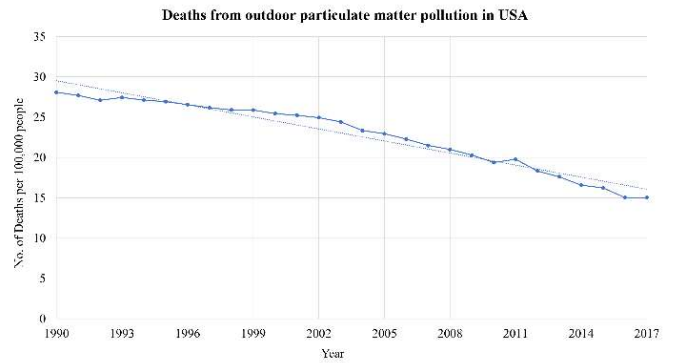

(c)

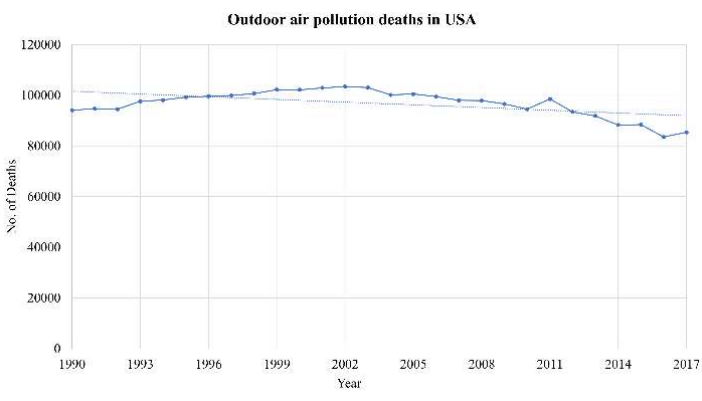

(e)

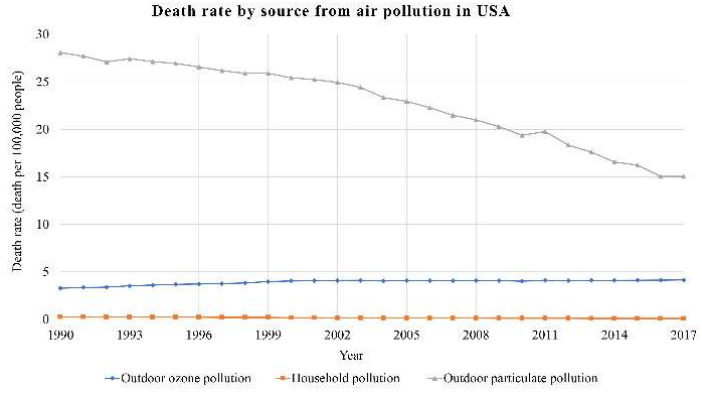

(g)

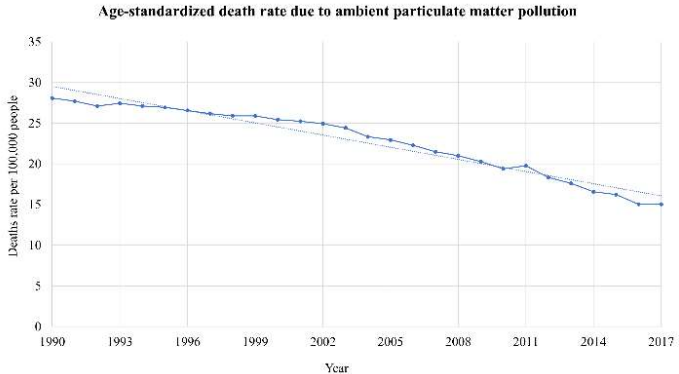

(b)

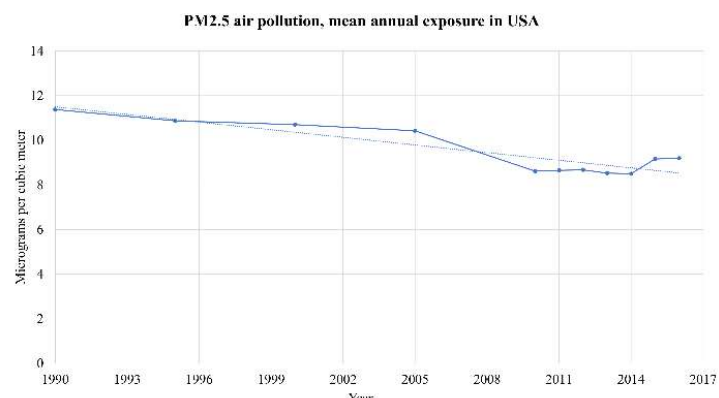

(d)

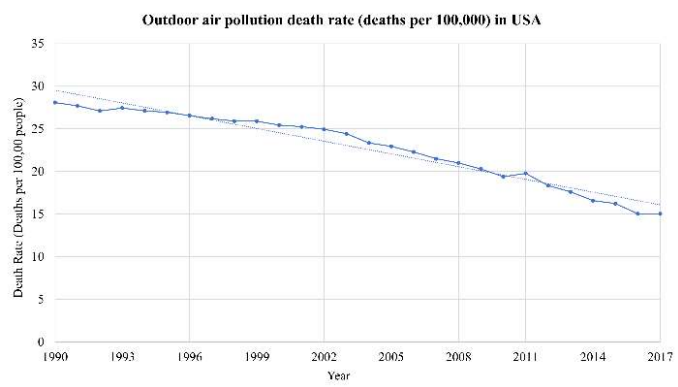

(f)

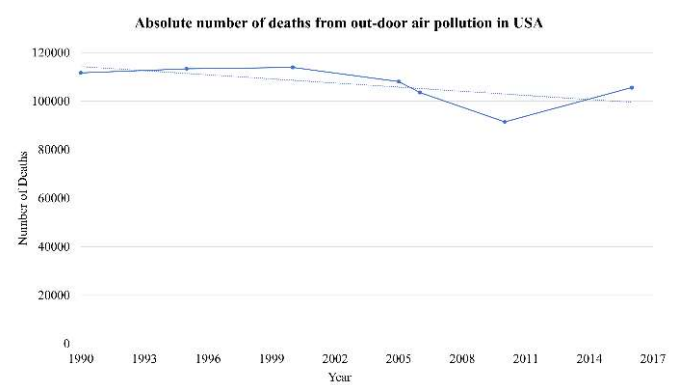

(h)

Figure 4. (a) Deaths due to ambient particulate air pollution; (b) Ambient air pollution age-standard death rate; (c) No. of deaths due to outdoor PM pollution; (d) Mean annual exposure of PM 2.5 overtime; (e) No. of deaths due to outdoor air pollution; (f) The death rate due to outdoor air pollution; (g) Death rate by different air pollution sources; (h) Absolute number of deaths due to outdoor air pollution.

The death rate due to air pollution in 1990 is 28.08 per 100,000 people with a population of 252,529 , and 950 . In 2017, the death rate is 15.04 per 100,000 people with a population of 324,459, and 463. This shows that there is a decrease in the death rate despite an 
increase in the population. There is also a decrease in deaths due to outdoor particulate matter air pollution over time (see Figure 4(a) and Figure 4(c)).

The industries are one of the major sources of outdoor particulate pollution. Mobile sources are another major source and are not considered in this study. A correlation analysis was conducted between the deaths from outdoor particulate matter pollution and four different types of RSEI scores (RSEI Non-Cancer score for Modeled Media, RSEI Total Non-Cancer RSEI score, RSEI Cancer score for Modeled Media, RSEI Total Cancer score) to identify the significant relationship between them for the period of 2007 to 2017. The choice of the year 2007 is due to the fact that one could generate RSEI for particulate releases from 2007. Pearson, Spearman, and Kendall correlation techniques are used to find the correlation among the two variables with $95 \%$ confidence. In Table $3, r$, rho, and tab B are Pearson, Spearman, and Kendall coefficients and $p$ is the measure of significance. Figure 5 represent the individual correlation scatter plots with each type of RSEI score. The null hypothesis is assumed and indicates that the relation between the deaths from outdoor particulate matter pollution and RSEI scores does not exist.

Table 3. Correlation Table of deaths from outdoor particulate matter pollution and RSEI.

\begin{tabular}{|c|c|c|c|c|c|c|c|c|}
\hline & & & \multicolumn{2}{|l|}{ Pearson } & \multicolumn{2}{|c|}{ Spearman } & \multicolumn{2}{|l|}{ Kendall } \\
\hline & & & $r$ & $p$ & rho & $p$ & $\operatorname{tau} B$ & $p$ \\
\hline $\begin{array}{l}\text { Deaths from outdoor par- } \\
\text { ticulate matter pollution } \\
\text { (deaths per } 100,000)\end{array}$ & - & $\begin{array}{l}\text { RSEI Non-Cancer } \\
\text { score for Modeled } \\
\text { Media }\end{array}$ & $0.781^{* *}$ & 0.005 & $0.782^{* *}$ & 0.007 & $0.673^{* *}$ & 0.003 \\
\hline $\begin{array}{l}\text { Deaths from outdoor par- } \\
\text { ticulate matter pollution } \\
\text { (deaths per } 100,000)\end{array}$ & & $\begin{array}{l}\text { RSEI Total Non- } \\
\text { Cancer score }\end{array}$ & 0.586 & 0.058 & $0.664^{*}$ & 0.031 & 0.455 & 0.060 \\
\hline $\begin{array}{l}\text { Deaths from outdoor par- } \\
\text { ticulate matter pollution } \\
\text { (deaths per } 100,000)\end{array}$ & - & $\begin{array}{l}\text { RSEI Cancer score } \\
\text { for Modeled Me- } \\
\text { dia }\end{array}$ & $0.798^{* *}$ & 0.003 & $0.918^{* * *}$ & $<.001$ & $0.782^{* * *}$ & $<.001$ \\
\hline $\begin{array}{l}\text { Deaths from outdoor par- } \\
\text { ticulate matter pollution } \\
\text { (deaths per } 100,000)\end{array}$ & - & $\begin{array}{l}\text { RSEI Total Cancer } \\
\text { score }\end{array}$ & $-0.703 *$ & 0.016 & $-0.627^{*}$ & 0.044 & -0.455 & 0.060 \\
\hline
\end{tabular}

${ }^{*} \mathrm{p}<.05,{ }^{* *} \mathrm{p}<.01,{ }^{* * *} \mathrm{p}<.001$.

\section{Correlation Scatter Plots}

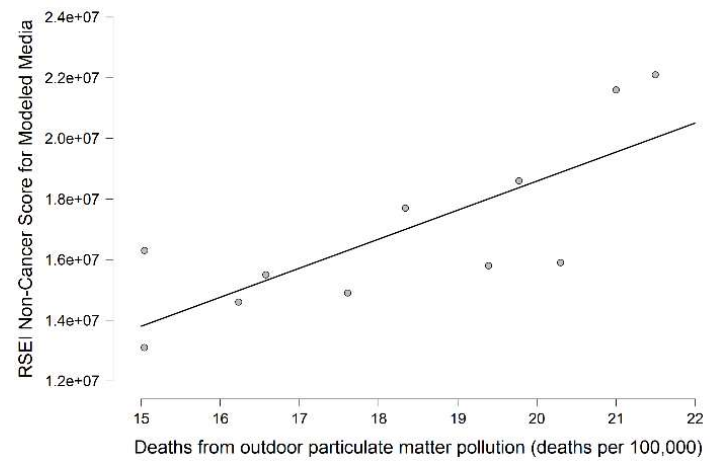

(a)

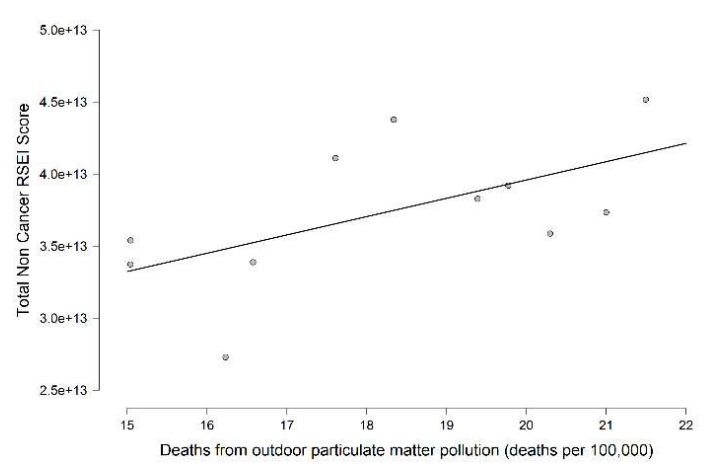

(b) 


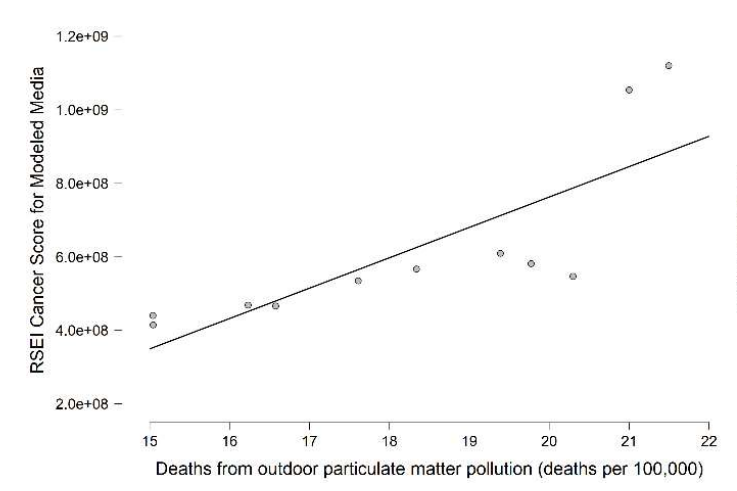

(c)

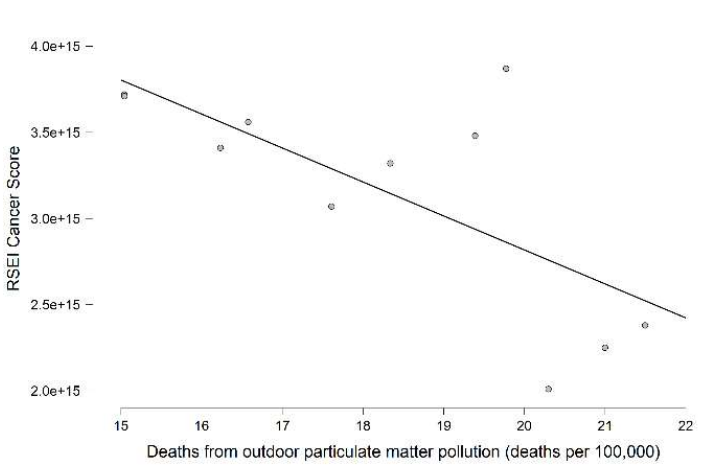

(d)

Figure 5. (a) Deaths from outdoor particulate matter pollution (deaths per 100,000) vs. RSEI Non-Cancer score for Modeled Media; (b) Deaths from outdoor particulate matter pollution (deaths per 100,000) vs. RSEI Total Non-Cancer score; (c) Deaths from outdoor particulate matter pollution (deaths per 100,000) vs. RSEI Cancer score for Modeled Media; (d) Deaths from outdoor particulate matter pollution (deaths per 100,000) vs. RSEI Total Cancer score.

The results for the Pearson, Spearman, and Kendall correlation analysis conducted between the deaths from outdoor particulate matter pollution and four different types of RSEI scores are shown in Table 3. The values of $r$, rho, and tau $B$ are negative for RSEI Cancer score and positive for all the other three types. The three methods show that there exists a negative correlation between the RSEI Cancer score and a positive correlation for the other three types of RSEI scores. The value of $r$, rho, and tau $B$ for the RSEI Non-Cancer score for Modelled Media are $0.781,0.782$, and 0.673 respectively. The $p$ values for these methods are lower and close to 0.001 , It shows that the relationship is significant. Overall results for RSEI Non-Cancer score for Modelled Media indicate that there exists a positive significant relation with the deaths from outdoor particulate matter pollution. Similarly, the value of $r$, rho, and tau B for the RSEI Cancer score for Modelled Media is 0.798, 0.918, and 0.782 respectively. The $p$ values for the three methods are lower and $<0.001$, It shows that the relationship is highly significant. The overall results for RSEI Cancer score for Modelled Media indicate that there is a positively high significant relation exists with the deaths from outdoor particulate matter pollution. When RSEI Non-Cancer score is considered, the value of $r$, rho, and tau $B$ is $0.586,0.664$, and 0.445 respectively. The $p$ values for the three methods are $>0.001$, shows that the relationship is moderately significant. The overall results for RSEI Non-Cancer score indicate that there exists a positively moderate significant relation with the deaths from outdoor particulate matter pollution. However, the RSEI Total Cancer score shows a negatively moderate significant relation as the $p$ values for the three methods are $>0.001$ and the values of $r$, rho, and tau $B$ are -0.703 , 0.627 , and -0.455 respectively. If the relationship is positive, then if one variable increases then the other variable also increases and vice versa.

RSEI Cancer score for Modeled Media has the lowest $p$-value (0.003 for Pearson; $<0.001$ for Spearman, Kendall) and exhibits a positively high significant relation. RSEI cancer score explains the highest risk from the toxic releases and might affect the deaths due to air pollution. Modeled media is where P2 activities/initiatives were implemented. P2 activities are targeted to decrease air pollution releases along with releases into other media as a part of initiatives. If the RSEI Cancer score for Modeled Media has a positively high significant relation to deaths from outdoor air pollution then, it can be said that the increase in P2 activities led to a decrease in the RSEI Cancer score.

The overall analysis indicates that there is a necessity for P2 activities to minimize the RSEI Cancer score. This analysis also explains that there is some positive significance (may not be highly significant) in the relationship between deaths from outdoor particulate matter pollution and the P2 activities. As the analysis itself explains that this study is significant, and the null hypothesis can be rejected. 
In brief, P2 activities are essential for preserving groundwater sources, wetlands, ecosystems, the areas in which we especially want to stop pollution before it begins, and for reducing the levels of air pollutants. P2 practices help in improving overall public health and wellbeing as demonstrated by decreasing RESI scores for the modeled media and decreasing death rates. It is possible that there could be other possible reasons (reduction in smoking, maintaining healthy diet and increase fitness activities etc.,) for the decrease in the death rate due to air pollution. However, the implementation of EPA P2 activities in the industrial facilities led to a decrease in pollutant emissions and, therefore, had an impact on the reduction in the death rate.

\section{Conclusion}

Industrial source emissions are a major portion of total air pollution in the US. The number of pollutants due to industrial releases are going down with time as a result of air quality regulations and P2 activities. The information given in the paper shows that the total number of deaths due to different pollutants is reducing overtime. However, there is an increase in GDP along with an increase in population during the study period. The overall correlation analysis shows that deaths from outdoor particulate matter pollution are significantly correlated with RSEI Non-Cancer score and RSEI Cancer score for Modeled Media, and moderately correlated with RSEI Non-Cancer score. However, there is a negative correlation with the RSEI Cancer score since most of the industries are yet to implement the P2 initiatives. This shows us that the industrial facilities that have undergone P2 assessments and initiated implementation of recommendations are already started showing the differences (reductions) in the releases. The reason to be noted that the US EPA encouraged the P2 activities to address the challenges faced due to the exposure of ambient air pollution to public health and well-being. In this paper, it is observed qualitatively and statistically that P2 activities taken by USEPA have a significant impact on reducing the number of air pollutants from industries reported to TRI along with the death rates.

Funding: This research received no external funding.

Conflicts of Interest: The authors declare no conflict of interest.

\section{References}

1. WHO Regional Office for Europe, OECD (2015). Economic cost of the health impact of air pollution in Europe: Clean air, health and wealth. Copenhagen: WHO Regional Office for Europe.

2. Im, Ulas, et al. "Assessment and economic valuation of air pollution impacts on human health over Europe and the United States as calculated by a multi-model ensemble in the framework of AQMEII3." Atmospheric chemistry and physics18.8 (2018): 5967.

3. Heinsohn, R.J., and Kabel, R.L. Sources and control of air pollution: Engineering principles. United States: N. p., 1998. Web.

4. Publicintegrity.org (2019). [Online] Available at: https://publicintegrity.org/environment/industrial-waste-pollutes-americas-drinking-water/ [Accessed Oct. 2019]

5. USEPA, “Factors to Consider When Using Toxics Release Inventory Data”. (2019).

6. Epa.gov (2019). [Online] https://www.epa.gov/toxics-release-inventory-tri-program [Accessed Nov. 2019].

7. Saisantosh Vamshi Harsha Madiraju, Ashok Kumar., “Evaluation of Risk for Different Industrial Facilities using Toxic Release Inventory in Ohio", A\&WMA's 112th Annual Conference \& Exhibition, June (2019).

8. U.S. Cancer Statistics Working Group. United States Cancer Statistics: 1999-2011 Incidence and Mortality Web-based Report. Atlanta: U.S. Department of Health and Human Services, Centers for Disease Control and Prevention and National Cancer Institute; 2014. Available at: www.cdc.gov/uscs.

9. Sarigiannis, Dimosthenis A., Spyros P. Karakitsios, and Marianthi V. Kermenidou. "Health impact and monetary cost of exposure to particulate matter emitted from biomass burning in large cities." Science of The Total Environment 524 (2015): 319-330.

10. Martuzzi, M. "The economics of environment and health: costs of mortality and morbidity due to air pollution in Europe." Environmental Epidemiology 3 (2019): 263.

11. Seer.cancer.gov (2019). [Online] Available at: https://seer.cancer.gov/ [Accessed Nov. 2019].

12. Epa.gov (2019). [Online] https://www.epa.gov/report-environment/disease-and-conditions [Accessed Dec. 2019].

13. Møller, Peter, et al. "Air pollution, oxidative damage to DNA, and carcinogenesis." Cancer letters 266.1 (2008): 84-97. 
14. CDC.gov (2019). [Online] Available at: https://www.cdc.gov/nchs/index.htm [Accessed Dec. 2019].

15. Silva, Raquel A., et al. "The impact of individual anthropogenic emissions sectors on the global burden of human mortality due to ambient air pollution." Environmental health perspectives 124.11 (2016): 1776-1784.

16. Lewtas, Joellen. "Experimental evidence for the carcinogenicity of air pollutants." Air pollution and human cancer. Springer, Berlin, Heidelberg, 1990. 49-61.

17. National Toxicology Program. "14th report on carcinogens. 2016." Research Triangle Park: National Toxicology Program, USEPA, Department of Health and Human Services. June. Available at URL: http://ntp. niehs. nih. gov/ntp/roc/twelfth/roc12. pdf (2019).

18. Loomis, Dana, et al. "The carcinogenicity of outdoor air pollution." Lancet Oncology 14.13 (2013): 1262.

19. EPA.gov (2019). [Online] Available at: https://www.epa.gov/p2 [Accessed Dec. 2019].

20. Carvour, Martha L., et al. "Estimating the health and economic impacts of changes in local air quality." American journal of public health 108.S2 (2018): S151-S157.

21. edap.epa.gov (2019). [Online] Available at: https://edap.epa.gov/public/extensions/EasyRSEI/ [Accessed Dec. 2019].

22. Ourworlddata.org (2019). [Online] Available at: https://ourworldindata.org/air-pollution [Accessed Dec. 2019].

23. Stanford, Janet L., et al. "Prostate Cancer Trends 1973-1995, SEER Program, National Cancer Institute." NIH pub 99-4543 (1999).

24. Ries, Lynn AG, et al. "SEER cancer statistics review, 1975-2003." (2006).

25. Horner, M. J., et al. "SEER Cancer Statistics Review, 1975-2006, National Cancer Institute. Bethesda, MD." (2009): 545-76.

26. Boffa, Daniel J., et al. "Using the National Cancer Database for outcomes research: a review." JAMA oncology 3.12 (2017): $1722-1728$.

27. EPA.gov (2019). [Online] Available at: https://www.epa.gov/rsei/learn-about-rsei [Accessed Dec. 2019].

28. Kelly, James T., et al. "A system for developing and projecting PM2. 5 spatial fields to correspond to just meeting national ambient air quality standards." Atmospheric Environment: X 2 (2019): 100019.

29. Usman, Muhammad, et al. "Are air pollution, economic and non-economic factors associated with per capita health expenditures? Evidence from emerging economies." International journal of environmental research and public health 16.11 (2019): 1967.

30. Kampa, Marilena, and Elias Castanas. "Human health effects of air pollution." Environmental pollution 151.2 (2008): 362367.

31. Fofack, Achille Dargaud, Steve Yaw Sarpong, and Damis Ferouz Kamna. "Economic Growth and Air Pollution Dynamics: The Case of Canada." International Journal of Environmental Pollution and Environmental Modelling 2.1 (2019).

32. Gispub.epa.gov (2019). [Online] Available at: https://gispub.epa.gov/air/trendsreport/2017/ [Accessed Jan. 2020].

33. Zhang, Yuqiang, et al. "Long-term trends in the ambient PM2. 5-and O3-related mortality burdens in the United States under emission reductions from 1990 to 2010." Atmospheric chemistry and physics 18.20 (2018): 15003.

34. EPA.gov (2020). [Online] Available at: https://www.epa.gov/rsei/understanding-rsei-results. [Accessed Jan. 2020].

35. Nazhmetdinova, Aiman, Adlet Kassymbayev, and Altinay Chalginbayeva. "Evaluation of the carcinogenic risks at the influence of POPs." Reviews on environmental health 32.4 (2017): 373-378.

36. Saisantosh Vamshi Harsha Madiraju, Lakshika Kuruppuarachchi, Ashok Kumar and Matthew Franchetti, "P2 Approaches to Analyze Assessment Data". Proceedings of International Conference on Sustainable Solutions in Industrial Pollution, Water and Wastewater Treatment, pp. 7-9, November 10-11, (2018), ISBN: 978-93-88237-19-2.

37. Hannah Ritchie and Max Roser (2020) - "Air Pollution". Published online at OurWorldInData.org. Retrieved from: 'https://ourworldindata.org/air-pollution' [Online Resource]. 